\title{
SENSITIVITY OF MELT POOL DIMENSIONS AND KEYHOLE TO LASER BEAM DIAMETER
}

\author{
N. Hassine ${ }^{1}$, S. Chatti1*, M. Ben Slama1, L. Kolsi2,3 \\ ${ }^{1}$ Laboratory of Mechanical Engineering (LGM), National Engineering School of Monastir, Tunisia (ENIM), \\ University of Monastir, Rue Ibn El Jazzar, 5000 Monastir, Tunisia \\ ${ }^{2}$ Department of Mechanical Engineering, College of Engineering, University of Ha'il, \\ Ha'il City 81451, Saudi Arabia \\ ${ }^{3}$ Laboratory of Metrology and Energy Systems, Department of Energy Engineering, \\ University of Monastir, 5000 Monastir, Tunisia \\ *Corresponding author's e-mail address: sami.chatti@udo.edu
}

\begin{abstract}
The laser powder bed fusion process has witnessed a huge interest in recent years since it has the potential to produce challenging shapes in a broad range of applications. The process parameters have a considerable effect on melt pool size and on the development of defect porosity. This paper predicts numerically the effect of a large range of laser beam diameters on melt pool dimensions and on the occurrence of porosity defects such as keyhole. A series of single beads of Inconel IN625 was made using various combinations of beam diameters, scan speeds, and laser powers. The use of a large diameter was more suitable rather than a small diameter as it ensures a large and shallow heat affected zone, thus decreasing the development of the keyhole defect. Our numerical results correlate satisfactorily with experimental finding from literature.
\end{abstract}

KEYWORDS: laser powder bed fusion, single beads, laser beam diameter, melt pool size, keyhole defect.

\section{INTRODUCTION}

Nowadays, additive manufacturing (AM) becomes a real solution to manufacture unlimited shapes difficult even impossible to build using classic manufacturing processes. Among the forward-looking AM processes, we mention the laser powder bed fusion (LPBF). This technique consists in producing metal parts by fusing a very thin powder layer using a laser power according to a trajectory given by the CAD. The irradiated powder absorbs a quantity of laser and, subsequently, the powder particles merge and solidify rapidly, thus, forming a scanning line. Obviously, the construction of this single track is the first and the decisive step, as this scan path will typically be deposited several times until the final piece is obtained. Thus, single bead seems to be the primary significant element of 3D printed parts. Hence, studies based on single beads are crucial, on the one hand, for a broad understanding of the process and, on the other hand, to provide ideas about the optimal parameters from the start of construction, aiming at manufacturing parts with a perfect quality.

AM has many advantages, and it is used in several areas, however, the major downside of AM is the slowness of the production of large parts and the defect's development such as the porosity defect which threatens the part's quality. In order to reduce these issues, a variety of solutions have been proposed in literature. The first one is regarding the build rate, it can be enhanced either by increasing the layer thickness or scanning speed in a controlled way [1].

The second alternative is increasing the diameter of the laser beam to scan a wider zone of powder bed at once. This latter represents one of the primary key parameters offering information about melt pool (MP) characteristic and, therefore, part quality. Nevertheless, each parameter should be studied separately for a better grasping of their impact during this process.

The Inconel IN625 super alloys are well suited for the manufacture of parts for several domains. The high mechanical and corrosion resistance are the wellknown characteristics of this material. Yet, this superior strength of IN625 renders it very challenging for conventional subtractive processes. For this reason, it is a suitable candidate for the LPBF process [2]. An evaluation of existing research summarized in Table 1 proves that the majority of the existing research on LPBF using the IN625 concentrates on the production of parts using a layer thickness below $50 \mu \mathrm{m}$ [3] - [5] or scan speed less than $400 \mathrm{~mm} / \mathrm{s}$ [6], [7].

To the best of our knowledge, few researchers have addressed the question of the laser beam diameter 
Table 1. Summary of some available research on LPBF of Inconel IN625

\begin{tabular}{|l|l|c|}
\hline \multicolumn{1}{|c|}{ Process parameters } & \multicolumn{1}{|c|}{ Studied properties } & References \\
\hline \multirow{5}{*}{ Scan speed } & MP characteristic + porosity & {$[6],[7]$} \\
& Relative density + surface roughness + residual stress & {$[3]$} \\
& Relative density + MP size and shape & {$[4]$} \\
\hline \multirow{3}{*}{ Laser power } & MP characteristic + porosity $[6]$ \\
& Relative density + surface roughness + residual stress & {$[3]$} \\
& Relative density + MP size and shape & {$[4]$} \\
\hline Scan strategy & Microstructural anisotropy & {$[8]$} \\
\hline Laser beam diameter & Geometry and stability of MP + microstructure & {$[9]$} \\
\hline \multirow{3}{*}{ Hatch spacing } & Porosity & {$[3]$} \\
& Relative density + surface roughness + residual stress & {$[4]$} \\
\hline
\end{tabular}

influence on MP sizes and the generation of porosity defects using a large range of laser beam diameters. Most of the research is restricted to only a couple of values. To fill this gap, this paper sheds new light on the effect of a large range of spot sizes on MP dimensions and the porosity defect development. Optimizing process parameters experimentally is generally tedious, time-consuming [5] and costly. Therefore, employing numerical models reveals as a helpful tool.

\section{NUMERICAL MODEL DESCRIPTION}

A series of single beads was analyzed using the finite element commercial software Ansys Additive. The objective is to identify the MP geometry. The geometry relates to the MP length, depth, and width, as described in figure 1. A parametric simulation of a single bead is performed using the Inconel IN625 at a constant build layer value of $50 \mu \mathrm{m}$ and a bead length of $3 \mathrm{~mm}$. For the laser beam diameter, the whole allowable range was selected to better estimate its effect on the melt pool dimensions. The range varies from $20 \mu \mathrm{m}$ to 140 $\mu m$, which is the minimum and maximum values of the software, with a step of $20 \mu \mathrm{m}$. Concerning the scan speed, three values are selected $(400 \mathrm{~mm} / \mathrm{s}, 800 \mathrm{~mm} / \mathrm{s}$, and $1400 \mathrm{~mm} / \mathrm{s}$ ) in order to match the experimental conditions. Finally, for the laser power two values (200 $W$ and $400 W$ ) are chosen for the same reason mentioned above. To estimate numerically the effect of a higher laser power on the melt pool dimensions, the value of $700 \mathrm{~W}$ was added arbitrary, which represents the upper value allowed by the software.

Our finite element model in mesoscale, i.e., melt pool scale, assumes that the powder bed is a material in a solid phase with a density factor (set as 0.6 ) calibrated by the software. As the laser source scans the powder bed, the energy generated by the laser is absorbed by the powder and the initial temperature of the powder increases. As the temperature reaches the melting temperature, the material will be considered as a liquid. The melting temperature is a property of the material mentioned in the Ansys software material database.
Both thermal conductivity and specific heat capacity are temperature dependent. Tables 2 and 3 show the material properties and the chemical composition of the IN625.

Table 2. Material properties of Inconel IN625

\begin{tabular}{|l|c|}
\hline \multicolumn{1}{|c|}{ Material properties } & Values \\
\hline Powder absorptivity & 0.6 \\
Solid absorptivity & 0.4 \\
Melting temperature $\left({ }^{\circ} \mathrm{C}\right)$ & 1290 \\
Material density $\left(\mathrm{kg} / \mathrm{m}^{3}\right)$ & 8440 \\
\hline
\end{tabular}

The temperature field distribution satisfies the following equation of 3D heat conduction adopted by [11]:

$$
\rho c \frac{\partial T}{\partial t}=\frac{\partial}{\partial x}\left(k \frac{\partial T}{\partial x}\right)+\frac{\partial}{\partial y}\left(k \frac{\partial T}{\partial y}\right)+\frac{\partial}{\partial z}\left(k \frac{\partial T}{\partial z}\right)+Q
$$

Where $k, \rho$, and $\mathrm{c}$ are the thermal conductivity, the material density, and the specific heat capacity, $T, t$ are the temperature and the time and $Q$ is the heat source.

The model's boundary conditions are the thermal phenomena: the heat conduction is described by equation 1 and the heat convection $Q_{c}$ is defined by the following equation [11]:

$$
Q_{c}=h\left(T-T_{0}\right)
$$

Where $h, T$, and $T_{0}$ are the coefficient of thermal convection, the temperature, and the initial temperature.

The third thermal boundary condition is heat loss by radiation and it is not considered in our model.

The temperature of the powder bed is set to room temperature as the initial condition and can be defined as:

$$
T=T_{0}=22^{\circ} \mathrm{C}=295 \mathrm{~K}
$$




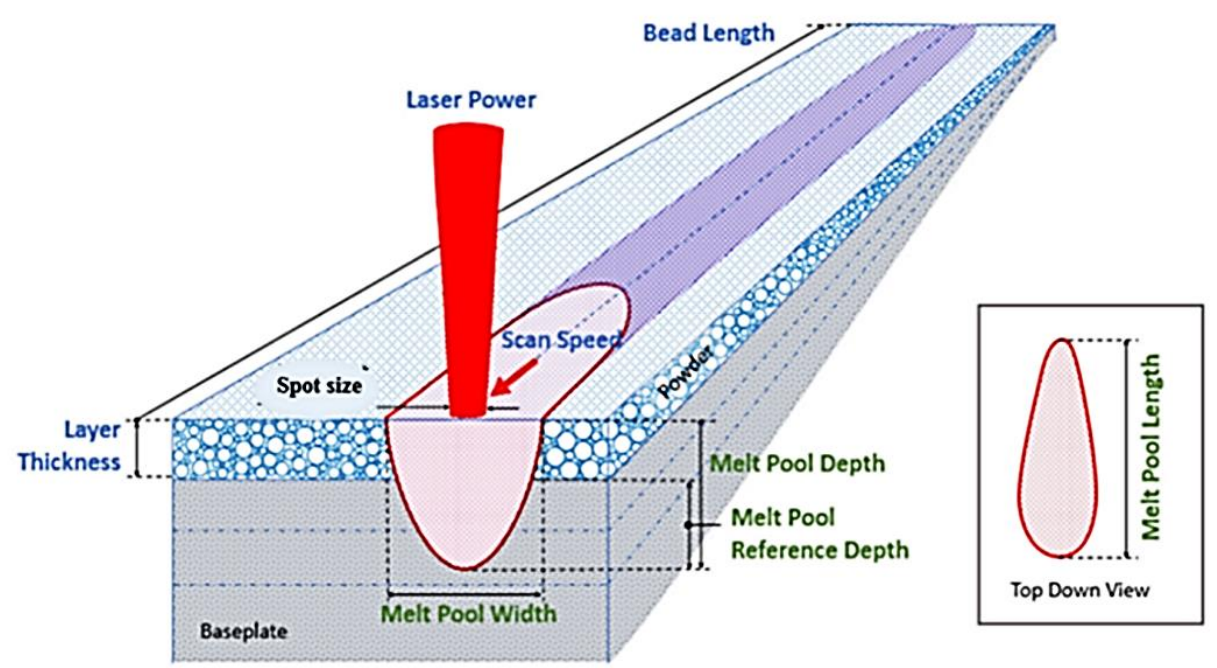

Fig. 1. Simplified schema of a single bead on powder showing MP dimensions [12]

Table 3. Chemical composition of IN625 powder [4]

\begin{tabular}{|c|c|c|c|c|c|c|c|c|c|c|c|c|c|}
\hline Element & $\mathrm{Cr}$ & $\mathrm{Mo}$ & $\mathrm{Fe}$ & $\mathrm{Nb}$ & $\mathrm{Co}$ & $\mathrm{Si}$ & $\mathrm{Ti}$ & $\mathrm{Al}$ & $\mathrm{Mn}$ & $\mathrm{P}$ & $\mathrm{S}$ & $\mathrm{C}$ & $\mathrm{Ni}$ \\
\hline $\begin{array}{c}\text { Composition } \\
\text { [wt \%] }\end{array}$ & 21.01 & 8.77 & 0.85 & 3.35 & 0.1 & 0.39 & 0.1 & 0.1 & 0.36 & 0.005 & 0.003 & 0.02 & Balance \\
\hline
\end{tabular}

For the heat source model, a Gaussian distribution of the heat flux is employed to model the movement of the laser beam, this model is commonly chosen by various researches [13]-[15].

Concerning the mesh, the process simulation involves elements with constant layer thickness along the entire building. To keep the coordinates fixed and for a better detection of the melt pool dimensions, the mesh type selected is Cartesian, i.e., structured. A finer mesh size is used with a value of $15 \mu \mathrm{m}$, almost 3 times smaller than the powder layer thickness of $50 \mu \mathrm{m}$. Ansys additive checks internally the mesh size.

\section{RESULTS AND DISCUSSION}

\subsection{Melt Pool Size}

Figure 2 depicts the laser beam diameter's effect on the MP depth under varying scan speeds and laser powers. As we can see, a clear trend of MP depth is found. This latter decreases with the increase of the laser beam diameter. With a constant speed $v=400 \mathrm{~mm} / \mathrm{s}$ (Fig. 2.a), when the laser beam diameter increases the MP depth drops rapidly from $395 \mu \mathrm{m}$ to $100 \mu \mathrm{m}$ (2 times the thickness of the powder layer) with a comparatively reduced power $p=200 \mathrm{~W}$. Whereas by increasing the laser power $p=400 \mathrm{~W}$ the depth remains almost constant until the diameter value $100 \mu \mathrm{m}$ where it starts to decrease.

For a high laser power of $700 \mathrm{~W}$, the depth is almost constant, and it registers a slight decrease for the diameter $140 \mu \mathrm{m}$. When power increases from 200 $W$ to $700 W$, for the diameter $140 \mu \mathrm{m}$, the depth increases almost 3 times, it passes from $106 \mu \mathrm{m}$ to 362 $\mu \mathrm{m}$. So, as the diameter increases, the effect of the laser power becomes more pronounced. Indeed, at small diameters less than $80 \mu \mathrm{m}$ the laser power has a relatively weak effect, whereas when the diameter increases to $140 \mu \mathrm{m}$ the depth becomes very sensitive to the laser power.

The same curves are observed when using a laser power value of $400 W$ (Fig. 2.b) and increasing the scan speed from $400 \mathrm{~mm} / \mathrm{s}$ up to $1400 \mathrm{~mm} / \mathrm{s}$. The large laser spot size is more responsive than the small laser spot size to the scan speed, where the depth decreases 4 times from $212 \mu \mathrm{m}$ to $53 \mu \mathrm{m}$ for a fixed spot size of $140 \mu \mathrm{m}$.

Concerning the width of the MP (Fig. $3 \mathrm{a}$ and b), it is obvious that enlarging spot diameter is followed by a broader MP width. Indeed, using a $140 \mu \mathrm{m}$ spot diameter at a fixed scan speed of $400 \mathrm{~mm} / \mathrm{s}$ and higher laser power of $700 \mathrm{~W}$ leads to a very broad melt pool width equal to $332 \mu \mathrm{m}$ which is almost 2.5 times the laser beam diameter (Fig. 3a). This aspect may be due to the higher and concentrated heat followed by a relatively slow scan speed of $400 \mathrm{~mm} / \mathrm{s}$, which in turn allows a long interaction time between powder and heat source, thus, a large melt pool width is created.

Another result that can be extracted from these figures is that for large diameters greater than $100 \mu \mathrm{m}$ the width becomes more sensitive to the variation of laser rather than for small diameters. In an attempt to validate our results, the predicted MP width and depth were verified against measured experimental data from literature [9] under similar conditions. 

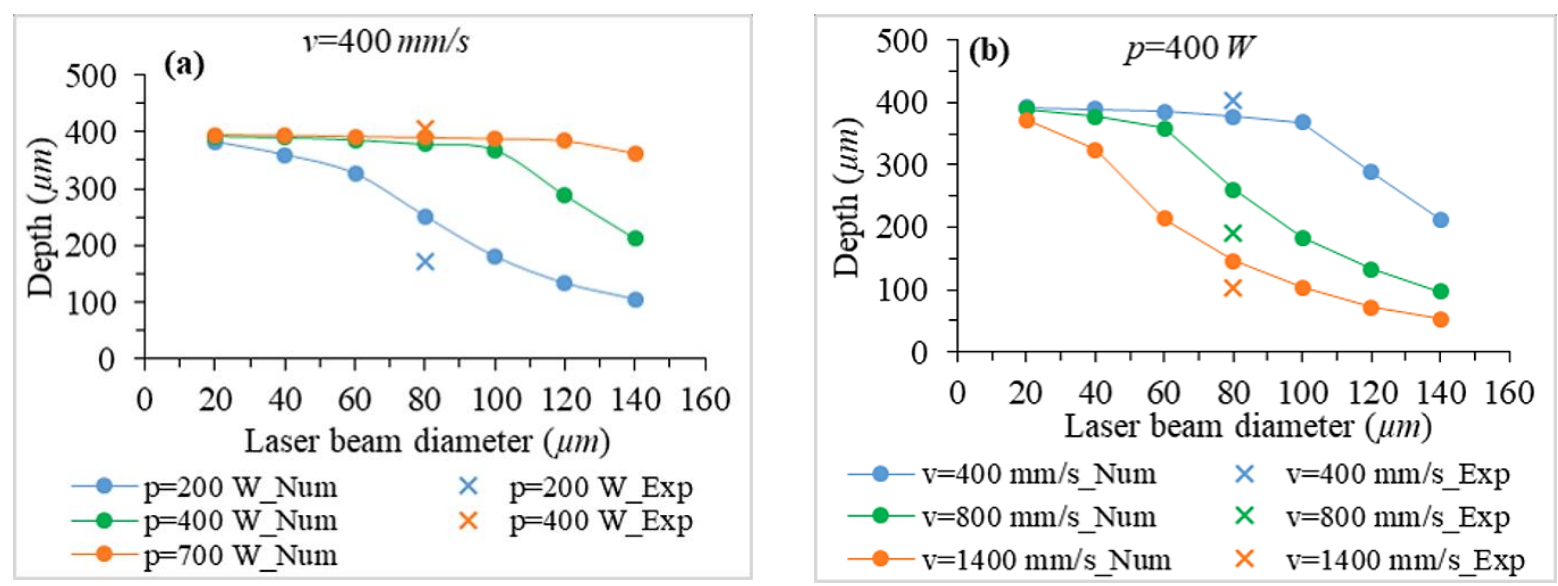

Fig. 2. MP depth at various beam diameters using different (a) laser powers (b) scan speeds

\subsection{Experimental Procedure Description}

Sow et al. [9] have analyzed experimentally the melt pool depth and width formed during LPBF process using various combinations of process parameters (spot size, laser power, and scanning speed). Samples were carried out on a powder layer with a thickness of $50 \mu \mathrm{m}$ under an argon atmosphere. Two laser sources of $1 \mathrm{~kW}$ and $2 \mathrm{~kW}$ were used to study the effect of two different spot sizes of $80 \mu \mathrm{m}$ and $500 \mu \mathrm{m}$ respectively on the melt pool dimensions. Laser power and scanning speed were then fixed to reach the desired volumetric energy density. During the print, the fusion zone was recorded using two Photron MC2 high speed cameras, and the morphology of the surfaces was investigated by means of a 3D sensor.

\subsection{Comparison between Numerical and Experimental Results}

Numerical analyses have simulated the experimental conditions reported by Sow et al. [9], the same material with the exact parameters was considered in the numerical investigation. The same layer thickness fixed at $50 \mu \mathrm{m}$, the same laser beam spot diameters of $80 \mu \mathrm{m}$, and the same combinations of laser power and scan speed have been selected in the simulations.

The predicted results proceed very much in the same way as indicated in the experimental measurements with a percentage error varying between $1.6 \%$ and $36 \%$ (Table 4).

However, some assumptions were considered for simplification reasons in the numerical study, which could present some errors and may be the source of differences between numerical and experimental results. For example, experimentally, the LPBF process was achieved under a constant argon gas, which cannot be simulated numerically, and can only be assumed as convection with the surrounding atmosphere on boundary conditions. Furthermore, in the numerical model, the powder bed was assumed as a homogenous continuum medium, which is not the case in the experimental process, where the powder particles do not have a fixed diameter and the powder bed was manually distributed. A possible explanation for this discrepancy is that for predefined material in the Ansys Additive (c) database, parameters were calibrated to reduce such deviations.
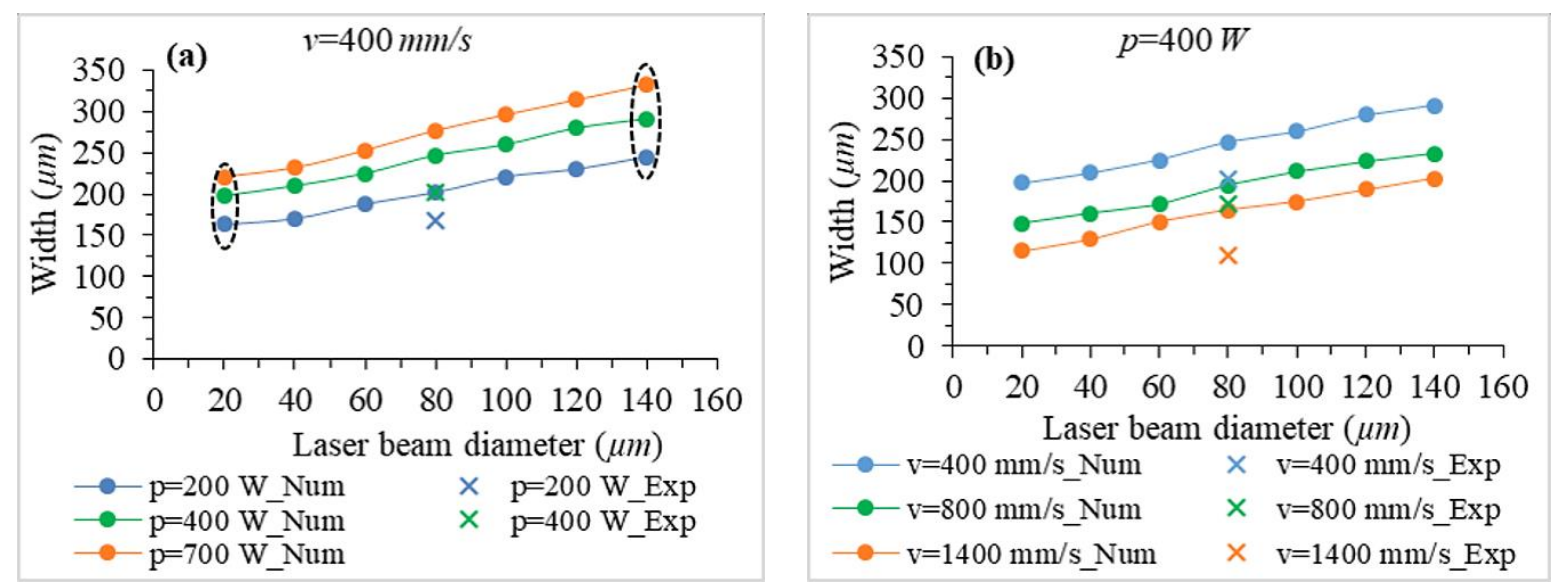

Fig. 3. MP width at various beam diameters using different (a) laser powers (b) scan speeds 
For the melt pool length, at fixed scan speed 400 $\mathrm{mm} / \mathrm{s}$ (Fig. 4 a), when using large diameters exceeding $80 \mu \mathrm{m}$, the laser power effect becomes very visible. In fact, for the combination of the diameter and the power
(140 $\mu \mathrm{m}-200 \mathrm{~W}$ ) the length is equal to $732 \mu \mathrm{m}$ while for the combination $(140 \mu \mathrm{m}-700 \mathrm{~W})$ the length has doubled almost 2.5 times and reaches the value $1890 \mu \mathrm{m}$.

Table 4. Comparison of predicted MP depth and width with experimental results [9]

\begin{tabular}{|c|c|c|c|c|}
\hline $\begin{array}{c}\text { Laser power } \\
{[W]}\end{array}$ & $\begin{array}{c}\text { Scan speed } \\
{[\mathrm{mm} / \mathrm{s}]}\end{array}$ & Depth_Num [ $\mu \mathrm{m}]$ & Depth_Exp [ $\mu \mathrm{m}[$ & $\begin{array}{c}\text { Relative error } \\
{[\%]}\end{array}$ \\
\hline 200 & 400 & 252 & $171 \pm 20$ & -31.9 \\
\hline 400 & 400 & 378 & $404 \pm 32$ & 1.6 \\
\hline 400 & 800 & 260 & $191 \pm 15$ & -26.21 \\
\hline 400 & 1400 & 146 & $104 \pm 10$ & -28 \\
\hline $\begin{array}{c}\text { Laser power } \\
{[\mathrm{W}]}\end{array}$ & $\begin{array}{c}\text { Scan speed } \\
{[\mathrm{mm} / \mathrm{s}]}\end{array}$ & Width_Num [ $\mu \mathrm{m}]$ & Width_Exp $[\mu \mathrm{m}]$ & $\begin{array}{c}\text { Relative error } \\
{[\%]}\end{array}$ \\
\hline 200 & 400 & 202 & $167 \pm 22$ & -6.87 \\
\hline 400 & 400 & 247 & $202 \pm 25$ & -8.8 \\
\hline 400 & 800 & 195 & $173 \pm 12$ & -5.4 \\
\hline 400 & 1400 & 165 & $109 \pm 12$ & -36 \\
\hline
\end{tabular}
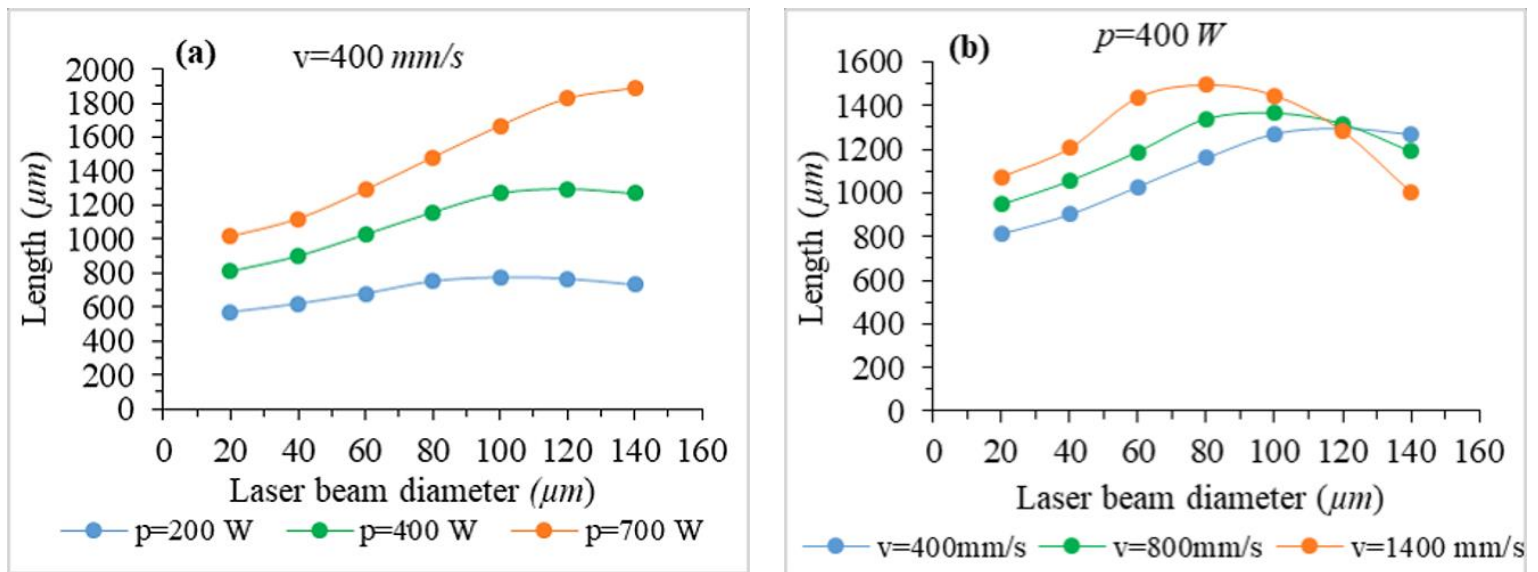

Fig. 4. Predicted MP length at various beam diameters using different (a) laser powers (b) scan speeds

The scan speed influence on MP length is also ambiguous and raises doubts. As we can see for small diameters beneath $100 \mu \mathrm{m}$, the length increases with the increase of the speed, while at wide spots greater than $100 \mu \mathrm{m}$ the length behaves in the opposite way.

However, the MP length trend, at fixed laser power $p=400 \mathrm{~W}$, is unclear. In fact, we distinguish two behaviors of the MP length (Fig. 4 b). The small diameter cases (below $80 \mu \mathrm{m}$ ) show an increase in length with increasing laser beam diameter, which is evident, indeed, enlarging diameter extends the heat affected zone and, consequently, the length of the MP. While the large diameter cases (above $100 \mu \mathrm{m}$ ) indicate a minor diminution in MP length.

In general, this discrepancy can be due to both numerical and experimental errors. Concerning the experimental error, the measurement of MP length is, with no doubt, delicate because it is on the basis of the identification of the liquid-solidus transition [16] and can generate measurement errors. Moreover, until now, there is no experimental measurement on IN625 melt pool length except the study of Heigel and Lane [16], to better understand and compare the melt pool length effect. Concerning errors related to the numerical model, they can be related, as stated above, to the nonconsideration of the dynamic fluid mechanisms and to the material properties in the powder state.

\subsection{Keyhole Appearing}

After the parametric simulations on a single scan line, we have extended our analysis to include the laser spot size influence on the development of porosity defects, more specifically the keyhole defect. This latter is characterized by the formation of a large cavity, which penetrates the MP in depth.

This defect strongly depends on the choice of the combination of laser power, laser spot size, and scan speed. The major factor for a keyhole MP is the elongation of the MP along the depth direction. Thus, some criteria related to the MP dimension may help to define the thresholds for the occurrence of such defect. 


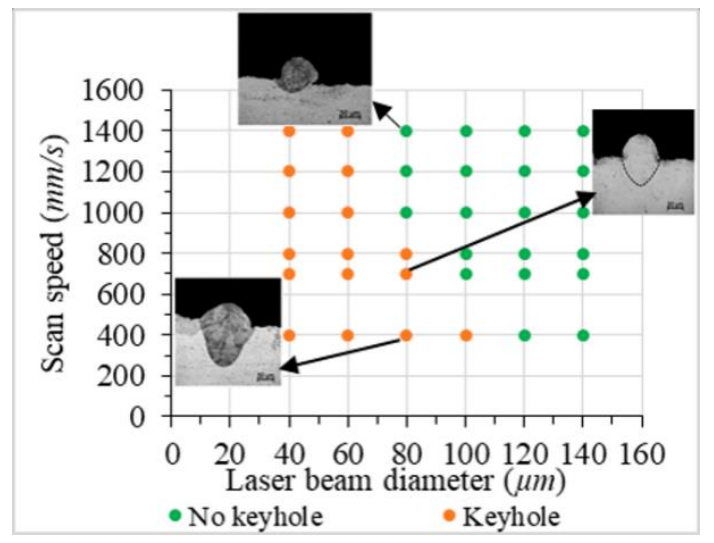

Fig. 5. Prediction of keyhole defects appearing and comparison with morphologies from literature [9]
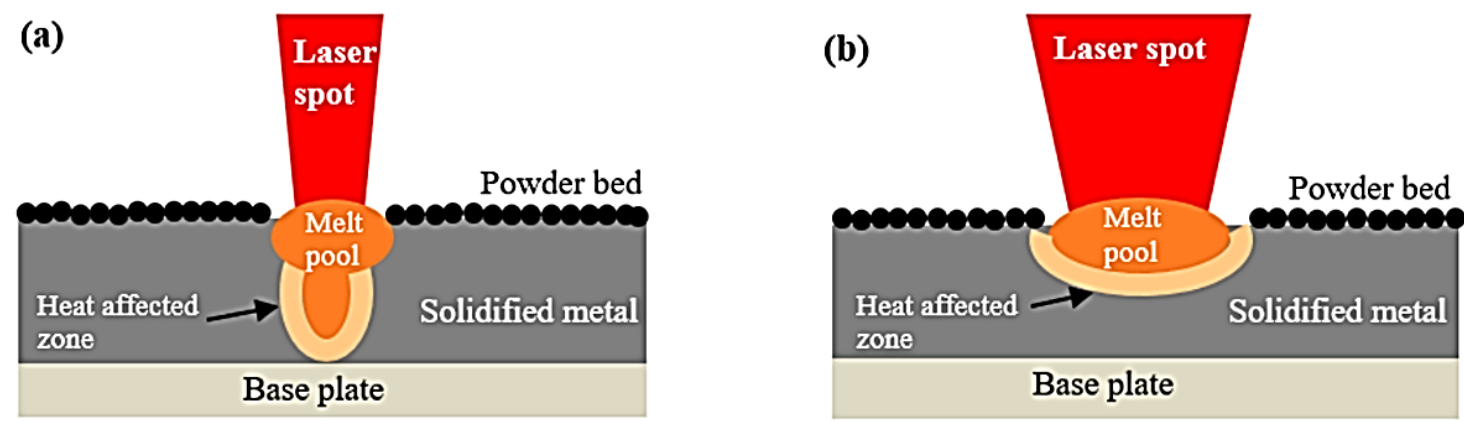

Fig. 6. Schematic demonstrating the spot size effect on the MP and the heat-affected zone using (a) a small laser beam diameter and (b) a large laser beam diameter

Aiming at producing parts free from the keyhole defect, Johnson et al. [11] proposed the following ratio:

$$
W / D>1.5 \quad[11]
$$

where $W$ and $D$ are the width and the depth of the MP.

Figure 5 presents the keyhole defects corresponding to several combinations of scan speed and laser spot size.

For small diameters below $80 \mu \mathrm{m}$, the keyhole defect is observed regardless of the speed. In fact, the use of small diameters with low speeds leads to an energy density centralized on a confined zone combined with a long-time of interaction between the material and the heat source. This could raise the temperature to the evaporation temperature, which leads to an evaporation pressure in the depth direction, resulting from the material's evaporation and, thus, to the formation of a deep cavity called the keyhole. However, with the increase of the diameter and regardless of the speed, the MP width is enhanced, and the depth is reduced resulting in a wider and shallower heat affected zone as demonstrated in figure 6.

The morphologies extracted from literature [9] in order to validate our numerical results were investigated using mechanical profilometer. After printing, IN625 samples were polished and analysed on cross sections by means of an Imager optical microscope. The analysis of the porosity rate was made using a 50x magnification at high resolution.
Microstructure analyses were carried out on samples chemically etched using a scanning electron microscope. The morphologies extracted from literature match well with our predicted results. As we can see in figure 5 , for the two combinations of laser beam diameter-scan speed $(80 \mu \mathrm{m}-400 \mathrm{~mm} / \mathrm{s})$ and $(80$ $\mu m-700 \mathrm{~mm} / \mathrm{s})$, both numerical and experimental findings prove the occurrence of the keyhole defect. For the combination $(80 \mu \mathrm{m}-1400 \mu \mathrm{m} / \mathrm{s}$ ), a good agreement is also found between numerical and experimental results.

In summary, the laser beam diameter contributes decisively to the development of keyhole defects, while the scan speed effect is less significant.

\section{CONCLUSIONS}

Single beads parametric simulations of the IN625 alloy were developed and analysed to evaluate the relationship between the laser beam diameter, MP sizes, and porosity defect formation using a finite element model on mesoscale, i.e., melt pool scale. Our numerical method represents an alternative tool, on the one hand, offering a prosperous approach limiting the experimental time and cost. On the other hand, it can be used for a deep grasp of process parameters influence on melt pool size and on the generation of porosity defects such as the keyhole. Our findings reveal that the diameter significantly affects the MP 
dimensions and, therefore, the quality of 3D printed parts. The combination of large diameters and high scan speeds is highly preferred since it allows to gain a larger MP and, subsequently, a larger and shallower heat affected zone, which in turn helps to avoid certain porosity defects such as the keyhole. This combination is also preferred as it saves time and, subsequently, increases the build rate. However, the increase in speed must be controlled to avoid the development of balling defects related to excessive speed increase. The powder layer thickness and the hatch spacing seem to be other crucial parameters that should be taken into consideration in an attempt to produce $3 \mathrm{D}$ printed parts free from porosity defects. Therefore, further studies on the current topic are required.

\section{REFERENCES}

[1] Leicht A., Fischer M., Klement U., Nyborg L., and Hryha E., Increasing the productivity of laser powder bed fusion for stainless steel $316 \mathrm{~L}$ through increased layer thickness, J. Mater. Eng. Perform., vol. 30, no. 1, pp. 575-584, 2021, doi: 10.1007/s11665-020-05334-3.

[2] Pleass C., Jothi S., Influence of powder characteristics and additive manufacturing process parameters on the microstructure and mechanical behaviour of Inconel 625 fabricated by Selective Laser Melting, Addit. Manuf., vol. 24, pp. 419-431, 2018, doi: 10.1016/j.addma.2018.09.023.

[3] Balbaa M. A., Elbestawi M. A., and McIsaac J., An experimental investigation of surface integrity in selective laser melting of Inconel 625, Int. J. Adv. Manuf. Technol., vol. 104, no. 912, pp. 3511-3529, 2019, doi: 10.1007/s00170-019-03949-y.

[4] Criales L. E., Arisoy Y. M., Lane B., Moylan S., Donmez A., and Özel T., Laser powder bed fusion of nickel alloy 625: Experimental investigations of effects of process parameters on MP size and shape with spatter analysis, Int. J. Mach. Tools Manuf., vol. 121, no. September, pp. 22-36, 2017, doi: 10.1016/j.ijmachtools.2017.03.004.

[5] Criales L. E., Arisoy Y. M., Lane B., Moylan S., Donmez A., Özel T., Predictive modeling and optimization of multi-track processing for laser powder bed fusion of nickel alloy 625, Addit.
Manuf., vol. 13, pp. 14-36, 2017, doi: 10.1016/j.addma.2016.11.004.

[6] Wang L., Wei Q., Shi Y., Liu J., He W., Experimental investigation into the single-track of selective laser melting of IN625, Adv. Mater. Res., vol. 233-235, pp. 2844-2848, 2011, doi: 10.4028/www.scientific.net/AMR.233-235.2844.

[7] Li C., Guo Y. B., Zhao J. B., Interfacial phenomena and characteristics between the deposited material and substrate in selective laser melting Inconel 625, J. Mater. Process. Technol., vol. 243, pp. 269-281, 2017, doi: 10.1016/j.jmatprotec.2016.12.033.

[8] Condruz M. R., Matache G., Paraschiv A., Frigioescu T. F Badea T., Microstructural and tensile properties anisotropy of selective laser melting manufactured in 625, Materials (Basel)., vol. 13, no. 21, pp. 1-22, 2020, doi: 10.3390/ma13214829.

[9] Sow M. C., De Terris T., Castelnau O., Hamouche Z., Coste F., Fabbro R., Peyre P., Influence of beam diameter on Laser Powder Bed Fusion (L-PBF) process, Addit. Manuf., vol. 36, no. July, p. 101532, 2020, doi: 10.1016/j.addma.2020.101532.

10] Nayak S. K., Mishra S. K., Jinoop A. N., Paul C. P., Bindra K. S., Experimental Studies on Laser Additive Manufacturing of Inconel-625 Structures Using Powder Bed Fusion at 100 pm Layer Thickness, J. Mater. Eng. Perform., vol. 29, no. 11, pp. 76367647, 2020, doi: 10.1007/s11665-020-05215-9.

[11] Johnson L., Mahmoudi M., Zhang B., Seede R., Huang X., Maier J.T., Maier H.J., Karaman I., Elwany A., Arróyave R., Assessing printability maps in additive manufacturing of metal alloys, Acta Mater., vol. 176, pp. 199-210, 2019, doi: 10.1016/j.actamat.2019.07.005.

[12] Canonsburg A. D., "Additive User' s Guide (Print and Science)," 2019.

[13] Luo Z., Zhao Y., Efficient thermal finite element modeling of selective laser melting of Inconel 718, Comput. Mech., vol. 65, no. 3, pp. 763-787, 2020, doi: 10.1007/s00466-019-01794-0.

[14] Roberts I. A., Wang C. J., Esterlein R., Stanford M., Mynors D. J., "A three-dimensional finite element analysis of the temperature field during laser melting of metal powders in additive layer manufacturing," Int. J. Mach. Tools Manuf., vol. 49, no. 1213, pp. 916-923, 2009, doi: 10.1016/j.ijmachtools.2009.07.004.

[15] Li Y., Gu D., "Parametric analysis of thermal behavior during selective laser melting additive manufacturing of aluminum alloy powder," Mater. Des., vol. 63, pp. 856-867, 2014, doi: 10.1016/j.matdes.2014.07.006.

[16] Heigel J. C., Lane B. M., "Measurement of the Melt Pool Length during Single Scan Tracks in a Commercial Laser Powder Bed Fusion Process," J. Manuf. Sci. Eng. Trans. ASME, vol. 140, no. 5, 2018, doi: 10.1115/1.4037571. 